\title{
High Glucose-Induced Oxidative Stress Increases the Copy Number of Mitochondrial DNA in Human Mesangial Cells
}

\author{
Ghada Al-Kafaji and Jamal Golbahar \\ Diagnostic Services Unit, Al-Jawhara Centre for Molecular Medicine, College of Medicine and Medical Sciences, \\ Arabian Gulf University, P.O. Box 26671, Manama, Bahrain \\ Correspondence should be addressed to Ghada Al-Kafaji; ghadaa@agu.edu.bh
}

Received 4 April 2013; Accepted 8 July 2013

Academic Editor: Stefano Curcio

Copyright (c) 2013 G. Al-Kafaji and J. Golbahar. This is an open access article distributed under the Creative Commons Attribution License, which permits unrestricted use, distribution, and reproduction in any medium, provided the original work is properly cited.

\begin{abstract}
Oxidative damage to mitochondrial DNA (mtDNA) has been linked to the pathogenicity of diabetic nephropathy. We tested the hypothesis that mtDNA copy number may be increased in human mesangial cells in response to high glucose-induced reactive oxygen species (ROS) to compensate for damaged mtDNA. The effect of manganese superoxide dismutase mimetic (MnTBAP) on glucose-induced mtDNA copy number was also examined. The copy number of mtDNA was determined by real-time PCR in human mesangial cells cultured in $5 \mathrm{mM}$ glucose, $25 \mathrm{mM}$ glucose, and mannitol (osmotic control), as well as in cells cultured in $25 \mathrm{mM}$ glucose in the presence and absence of $200 \mu \mathrm{M}$ MnTBAP. Intracellular ROS was assessed by confocal microscopy and flow cytometry in human mesangial cells. The copy number of mtDNA was significantly increased when human mesangial cells were incubated with $25 \mathrm{mM}$ glucose compared to $5 \mathrm{mM}$ glucose and mannitol. In addition, $25 \mathrm{mM}$ glucose rapidly generated ROS in the cells, which was not detected in $5 \mathrm{mM}$ glucose. Furthermore, mtDNA copy number was significantly decreased and maintained to normal following treatment of cells with $25 \mathrm{mM}$ glucose and MnTBAP compared to $25 \mathrm{mM}$ glucose alone. Inclusion of MnTBAP during $25 \mathrm{mM}$ glucose incubation inhibited mitochondrial superoxide in human mesangial cells. Increased mtDNA copy number in human mesangial cells by high glucose could contribute to increased mitochondrial superoxide, and prevention of mtDNA copy number could have potential in retarding the development of diabetic nephropathy.
\end{abstract}

\section{Introduction}

Hyperglycemia is the most important factor causing the development of progressive diabetic nephropathy $[1,2]$. In recent years, the mitochondrial dysfunctions and mitochondrial DNA (mtDNA) defects have been reported to be associated with the pathogenesis of diabetes and its complications. This diabetes-induced mtDNA defect has been highlighted in numerous studies by alteration of the mtDNA copy number [3-5]. Mitochondria are not only the main site of energy production, but also the major source of reactive oxygen species (ROS) generated as byproducts of oxygen metabolism. The human mitochondrial genome is a $16.6 \mathrm{~kb}$ circular double-stranded DNA with 1000-10,000 copies per cell [6], coding for proteins essential for cellular respiration and normal mitochondrial function.

Overproduction of mitochondrial superoxide during hyperglycemia has been postulated as the primary initiating mechanism that activates pathways of diabetes vascular tissue damage, leading to cellular redox imbalance and oxidative stress [7-9]. A number of in vitro and in vivo studies suggest that oxidative stress is increased in diabetic nephropathy [1012]. In addition, overproduction of ROS by high glucose compromises the antioxidant defense mechanisms in diabetic nephropathy such as reduced levels of mitochondrialspecific manganese superoxide dismutase (MnSOD) and further aggravates oxidative stress $[7,8,13]$. Oxidative stress including ROS may damage mtDNA and impair electron transport chain, leading to more ROS production [14, 15]. It is suggested that mtDNA, owing to its close proximity to the electron transport chain, lack of histone protection, and less DNA repair capacity, is a primary target to ROS attack $[15,16]$.

The copy number of mtDNA that reflects the abundance of mitochondria in a cell may change under different energy 
TABLE 1: Primers used for the amplification of mtDNA (ND2, CYTB) and nDNA (B2M).

\begin{tabular}{lccc}
\hline Gene & Sequence forward primer 5' to $3^{\prime}$ & Sequence reverse primer $5^{\prime}$ to $3^{\prime}$ & Length $(\mathrm{bp})^{\prime}$ \\
\hline NADH dehydrogenase subunit 2 (ND2) & CACAGAAGCTGCCATCAAGTA & CCGGAGAGTATATTGTTGAAGAG & 89 \\
Cytochrome b (CYTB) & TCATCGACCTCCCCACCCCATC & CGTCTCGAGTGATGTGGGCGATT & 165 \\
Beta-2-microglobulin (B2M) & TGGCCATACTACCCTGAATGAGTCC & ATGTATTGTGCAATGCTGCTGCTCG & 182 \\
\hline
\end{tabular}

demands and different physiological or environmental conditions [17]. It was observed that an increase in the mtDNA copy number per cell is associated with elevated oxidative stress in the human tissues of aged individuals $[18,19]$. A positive correlation between elevated oxidative stress and mtDNA copy number was found in the blood of hemodialysis patients [20]. The mtDNA copy number is also increased with increasing biomarkers of oxidative stress in human leukocytes [21].

In this study, we tested the hypothesis that high glucoseinduced oxidative stress may increase the copy number of mtDNA in human mesangial cells and examined the effect of MnSOD mimetic on high glucose-induced mtDNA copy number.

\section{Methods}

2.1. Human Mesangial Cells Culture and Treatment. Human mesangial cells (ScienCell Research Laboratories) from the third to sixth passage were maintained under conditions previously described $[22,23]$. For experimental studies, cells were grown to confluence, growth arrested in reduced serum ( $0.5 \%$ FBS $)$ for $24 \mathrm{~h}$, and were split into different experimental groups.

For treatment with different concentrations of glucose $[22,23]$, the cells were incubated in DMEM media (Sigma Aldrich) containing either $5 \mathrm{mM}$ glucose (normal glucose) or $25 \mathrm{mM}$ glucose (high glucose) for $24 \mathrm{~h}$ at $37^{\circ} \mathrm{C}$. Osmotic controls included the cells incubated in identical experimental conditions with $5 \mathrm{mM}$ glucose $+20 \mathrm{mM}$ mannitol instead of $25 \mathrm{mM}$ glucose.

For direct inhibition of mitochondrial superoxide radicals, the cells were incubated for $24 \mathrm{~h}$ with $25 \mathrm{mM}$ glucose in the presence or absence of $200 \mu \mathrm{M}$ MnTBAP (Mn(III)tetrakis(4-benzoic acid)) porphyrin chloride; a cell permeable mimetic of manganese superoxide dismutase (MnSOD) from Biomol, Plymouth Meeting, PA [24]. Control cells were allowed to grow in $5 \mathrm{mM}$ glucose. At the end of each experimental period, the cells were washed with Hanks' balanced salt solution (Gibco), harvested by trypsinization in $1 \mathrm{ml}$ PBS and used for the preparation of genomic DNA.

2.2. Genomic DNA Preparation. Genomic DNA was extracted by QIAamp DNA Mini Kit (Qiagen) according to the manufacturer's protocol. In brief, $200 \mu \mathrm{L}$ lysis buffer was added to cell pellets, mixed, and incubated at $56^{\circ} \mathrm{C}$ for $10 \mathrm{~min}$. Following centrifugation at 20,000 $\mathrm{g}$ for $1 \mathrm{~min}$, absolute ethanol $(200 \mu \mathrm{L})$ was added and the lysate was centrifuged at $6000 \mathrm{~g}$ for $1 \mathrm{~min}$, and washing procedures were carried out using washing buffers supplied with the kit. Genomic DNA was eluted by addition of elution buffer
$(200 \mu \mathrm{L})$ and stored at $-20^{\circ} \mathrm{C}$. All genomic DNA samples were sheared prior to use.

2.3. Primers and Polymerase Chain Reaction (PCR). Primers for NADH dehydrogenase subunit 2 (ND2) and cytochrome $\mathrm{b}$ (CYTB) genes were used as target sequences for determination of mitochondrial DNA. For the analysis of nuclear DNA, human beta-2-microglobulin (B2M) was selected as an internal reference gene. The primer sequences used for amplification of mitochondrial and nuclear DNA are listed in Table 1. The PCR reactions were performed in a total volume of $25 \mu \mathrm{L}$ reaction mixture, which contained DNA $(1 \mu \mathrm{g})$, forward and reverse primers $(50 \mathrm{ng} / \mu \mathrm{L}$ each), Taq DNA polymerase (1.25 U; Promega), $\mathrm{MgCl}_{2}$ (1.25 mM), 1X PCR reaction buffer, and NTPs $(2.5 \mathrm{mM})$. Amplification reactions were carried out for 30 cycles using an automated thermal cycle (Perkin-Elmer 2400) under the cycling parameters of denaturation at $95^{\circ} \mathrm{C}$ for $5 \mathrm{~min}$, annealing phase at $60^{\circ} \mathrm{C}$ for $1.5 \mathrm{~min}$, and extension at $70^{\circ} \mathrm{C}$ for $7 \mathrm{~min}$.

2.4. Cloning of PCR Products and Standard Preparation. The most convenient way to create a DNA standard is to clone a PCR product into a standard vector. For mtDNA and nDNA quantification by real-time PCR analysis, PCR products of ND2, CYTB, and B2M were purified using the GFX PCR DNA and gel band purification kit (GE Healthcare) and were cloned into the pGEM-T Easy Vector Systems (Promega) according to the manufacturer's instructions. The vectors were transformed into competent $E$. coli XL1 Blue cells and plasmid minipreps were prepared from selected positive clones using the Wizard plus SV Miniprep DNA Purification System (Promega). The clones were verified by sequencing (Geneservice), PCR amplification using genespecific primers, and restriction enzyme digestion using ApaI and PstI ( $12 \mathrm{U} / \mu \mathrm{L}$ each). For the generation of calibration curves, recombinant plasmids of ND2, CYTB, and B2M were linearized by single digestion using ApaI restriction enzyme $(12 \mathrm{U} / \mu \mathrm{L})$ and standard dilutions were prepared as previously described $[22,23]$, in which each gene is present in $10^{7}$ down to $10^{3}$ copies per $\mu \mathrm{L}$ and was used as calibration curves in the real-time PCR runs.

2.5. Real-Time PCR. The copy number of mtDNA per nuclear genome was assessed by real-time PCR using the LightCycler System and the FastStart DNA Master SYBR Green 1 Kit (Roche Molecular Biochemicals). Total genomic DNA (10 ng) was mixed with SYBR Green 1 probe, forward and reverse primers $(50 \mathrm{ng} / \mu \mathrm{L})$, and nuclease free water to the final volume of $10 \mu \mathrm{L}$. The reactions were performed in 40 cycles of denaturation at $95^{\circ} \mathrm{C}$ for $10 \mathrm{~min}$, amplification at $95^{\circ} \mathrm{C}$ 
for $10 \mathrm{sec}$, melting at $60^{\circ} \mathrm{C}$ for $10 \mathrm{sec}$, and cooling for $10 \mathrm{sec}$. The resulting data were analyzed using the Roche Molecular Biochemicals LightCycler software. The copy numbers of mtDNA and nDNA were calculated using the calibration curves that were constructed from dilution series of recombinant plasmids. The concentrations of mtDNA and nDNA were converted to copy numbers and calibration curves were plotted which are straight line of logarithm copy number $(x-$ axis) and threshold cycle $\left(C_{t}\right)$ of the reaction ( $y$-axis). Each measurement was carried out at least 3 times and normalized in each experiment against serial dilutions of a control DNA sample.

2.6. ROS Assay. Intracellular ROS production was detected in human mesangial cells using the redox-sensitive fluoroprobe carboxy-2 $2^{\prime}, 7^{\prime}$-dichlorodihydrofluorescein diacetate (carboxy- $\mathrm{H}_{2} \mathrm{DCFDA}$; Invitrogen) as previously described [22]. DCFDA is converted by intracellular esterases to $2^{\prime}, 7^{\prime}$-dichlorodihydrofluorescein, which, in turn, is oxidized by $\mathrm{H}_{2} \mathrm{O}_{2}$ to the highly fluorescent $2^{\prime}, 7^{\prime}$-dichlorodihydrofluorescein (DCF). Synchronized quiescent cells grown on glass coverslips were incubated with DMEM media (Sigma Aldrich) containing either $5 \mathrm{mM}$ glucose or $25 \mathrm{mM}$ glucose for $24 \mathrm{~h}$ at $37^{\circ} \mathrm{C}$. The cells were washed with PBS and incubated in the dark for $30 \mathrm{~min}$ with $25 \mu \mathrm{M}$ carboxy- $\mathrm{H}_{2}$-DCFDA dissolved in the culture media. For the positive control, cells incubated with $5 \mathrm{mM}$ glucose were treated with $100 \mu \mathrm{M}$ tetra-butyl hydroperoxide (TBHP) (Invitrogen) for $1 \mathrm{~h}$, washed and loaded with carboxy- $\mathrm{H}_{2}$-DCFDA. All cells were examined using a laser scanning confocal microscope (LSM 510; Zeiss, Oberkochen, Germany). H2DCFDA was detected on excitation of $488 \mathrm{~nm}$ and emission of $525 \mathrm{~nm}$.

In addition, a FACScan flow cytometer (Becton Dickinson, Bedford, MA, USA) equipped with a $488 \mathrm{~nm}$ argon laser was used for the flow-cytometric analysis to monitor intracellular ROS generation in human mesangial cells [22]. In brief, cells were incubated with $5 \mathrm{mM}$ glucose or $25 \mathrm{mM}$ glucose for $24 \mathrm{~h}$ at $37^{\circ} \mathrm{C}$, washed and loaded with carboxy$\mathrm{H}_{2}$-DCFDA ( $\left.25 \mu \mathrm{M}, 30 \mathrm{~min}\right)$ as above. Positive control cells were incubated with $5 \mathrm{mM}$ glucose in the presence of TBHP $(100 \mu \mathrm{M})$ for $1 \mathrm{~h}$, washed and loaded with carboxy- $\mathrm{H}_{2}-$ DCFDA. After incubation, cells were resuspended in PBS and used for flow cytometry analysis using an excitation wavelength of $488 \mathrm{~nm}$ and an emission wavelength of $525 \mathrm{~nm}$.

2.7. MitoSOX Red Analysis. The production of mitochondrial superoxide in human mesangial cells, was detected using MitoSOX red fluorogenic dye (Invitrogen). MitoSOX red permeates live cells, where it selectively targets mitochondria and is readily oxidized by superoxide. Synchronized quiescent cells grown on glass coverslips were incubated for $24 \mathrm{~h}$ at $37^{\circ} \mathrm{C}$ with $25 \mathrm{mM}$ glucose in the presence and absence of $200 \mu \mathrm{M}$ MnTBAP. Control cells were maintained in $5 \mathrm{mM}$ glucose. At the end of the incubation, MitoSOX $(5 \mu \mathrm{M})$ was added to the cells and incubated further for $20 \mathrm{~min}$ at $37^{\circ} \mathrm{C}$. The cells were washed with PBS and used for confocal microscopy. MitoSOX red was excited by laser at $514 \mathrm{~nm}$ and mean fluorescence
TABLE 2: Real-time PCR efficiency of mtDNA and nDNA standards.

\begin{tabular}{lccc}
\hline Gene & Slope & Efficiency (\%) & Error \\
\hline ND2 & -3.374 & 94 & 0.041 \\
CYTB & -3.31 & 99 & 0.020 \\
B2M & -3.30 & 100 & 0.010 \\
\hline
\end{tabular}

intensity per square millimeter cell area was calculated using Zeiss software.

2.8. Statistical Analysis. Student's $t$-test was used to compare the copy number of ND2 and CYTB per B2M in different conditions. Results were expressed as mean $\pm \mathrm{SD}$. All reported $P$ values are two tailed and a $P<0.05$ was considered to be statistically significant. The statistical analyses were performed using SPSS software, version 19.

\section{Results}

3.1. Verification of $m t D N A$ and $n D N A$ Inserts into pGEMT. The lengths of mtDNA and nDNA inserts were verified by PCR amplification and restriction enzyme digestion. The agarose gel electrophoresis result of PCR amplifications showed specific PCR products of the expected lengths of 89bp, 165-bp, and 182-bp that correspond to ND2, CYTB, and $\mathrm{B} 2 \mathrm{M}$, respectively, confirming the size of each insert (data not shown). In addition, the restriction enzyme analysis showed fragments of the same lengths of ND2, CYTB, and B2M inserts (data not shown).

3.2. Efficiency of Quantitative Real-Time PCR. For obtaining efficient amplification results, recombinant plasmids of ND2, $\mathrm{CYTB}$, and B2M were linearized and calibration curves were generated from duplicate measurements of 5 independent serial dilutions of each individual plasmid. The real-time PCR efficiency of each calibration curve was determined by plotting the $C_{t}$ value against the log template amount. From the slope $(S)$, the efficiency was calculated using the following formula:

$$
\text { efficiency }(\%)=\left(10^{(-1 / S)}-1\right) \times 100 \text {. }
$$

The corresponding amplification efficiencies, 94-100\%, were in the optimum range with a standard error mean of less than 0.05 (Table 2).

3.3. Effect of Glucose on mtDNA Copy Number. The effect of high glucose on mtDNA copy number in human mesangial cells is shown in Figure 1. The copy numbers of ND2 and CYTB per B2M were significantly increased by 2.5- and 2.6folds, respectively, when the cells were incubated with $25 \mathrm{mM}$ glucose compared to $5 \mathrm{mM}$ glucose $(P<0.05)$. Incubation of cells in $5 \mathrm{mM}$ glucose $+20 \mathrm{mM}$ mannitol (instead of $25 \mathrm{mM}$ glucose) did not have any effect on mtDNA copy number, suggesting that the effects observed under high glucose conditions were not induced by increased osmolarity. The mean ND2 copy number per copy of B2M gene was 


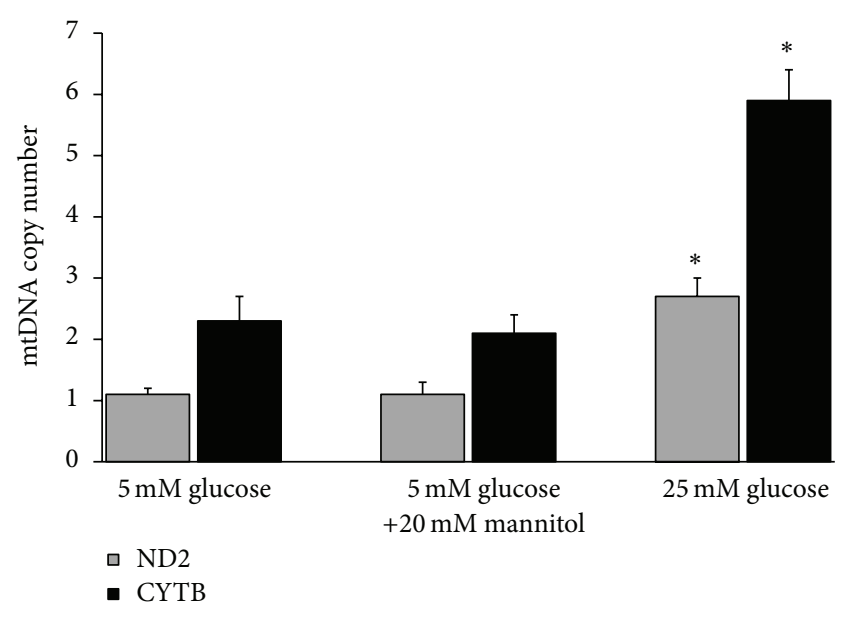

FIGURE 1: Effect of high glucose on mtDNA copy number. Synchronized quiescent mesangial cells were incubated with $5 \mathrm{mM}$ glucose, $25 \mathrm{mM}$ glucose, and $5 \mathrm{mM}$ glucose plus $20 \mathrm{mM}$ mannitol for $24 \mathrm{~h}$. The copy numbers of ND2 and CYTB per B2M were determined by real-time PCR. Values represent mean \pm SD of three independent experiments. ${ }^{*} P<0.05$ compared to $5 \mathrm{mM}$ glucose and to $5 \mathrm{mM}$ glucose plus $20 \mathrm{mM}$ mannitol.

$2.7 \pm 0.3$ in $25 \mathrm{mM}$ glucose compared to that of $5 \mathrm{mM}$ glucose $(1.1 \pm 0.1)$ and $5 \mathrm{mM}$ glucose $+20 \mathrm{mM}$ mannito $(1.1 \pm 0.2)$. Similarly, the mean CYTB copy number per copy of B2M gene was $5.9 \pm 0.5$ in $25 \mathrm{mM}$ glucose compared to that of $5 \mathrm{mM}$ glucose $(2.3 \pm 0.4)$ and $5 \mathrm{mM}$ glucose $+20 \mathrm{mM}$ mannitol $(2.1 \pm 0.3)$.

3.4. Accumulation of ROS in High Glucose-Treated Human Mesangial Cells. The accumulation of intracellular ROS by high glucose in human mesangial cells was assessed by confocal microscopy and flow cytometry using the redox-sensitive fluoroprobe carboxy- $2^{\prime}, 7^{\prime}$-dichlorodihydrofluorescein diacetate (carboxy- $\mathrm{H}_{2} \mathrm{DCFDA}$ ). As shown in Figures 2(a) and 2(b), production of ROS was observed following exposure of the cells to $25 \mathrm{mM}$ glucose as detected by higher DCFfluorescent intensity compared to $5 \mathrm{mM}$ glucose. Furthermore, a strong DCF-fluorescent signal was detected in the positive control cells that were maintained in $5 \mathrm{mM}$ glucose and treated with tetra-butyl hydroperoxide (TBHP) compared to cells maintained in $5 \mathrm{mM}$ glucose alone.

3.5. Effect of MnTBAP on mtDNA Copy Number. The effect of direct inhibition of mitochondrial superoxide by MnTBAP on mtDNA copy number induced by high glucose in human mesangial cells is shown in Figure 3.

Addition of MnTBAP during high glucose incubation prevented the increase in mtDNA copy number, as the mean ND2 copy number per copy of B2M gene was $1.1 \pm 0.3$ and was significantly decreased by 2.0 -fold when the cells were maintained in $25 \mathrm{mM}$ glucose plus MnTBAP compared to that of $25 \mathrm{mM}$ glucose without MnTBAP $(2.2 \pm 0.1)(P<$ $0.05)$. In a similar manner, the mean CYTB copy number per B2M copy number gene $(1.7 \pm 0.3)$ was significantly decreased by 2.7 -fold when the cells were incubated with $25 \mathrm{mM}$ glucose in the presence of MnTBAP compared to cells incubated with $25 \mathrm{mM}$ glucose in the absence of MnTBAP $(4.6 \pm 0.3)(P<$ 0.05).

3.6. Inhibition of High Glucose-Induced Mitochondrial Superoxide in Human Mesangial Cells. The direct inhibition of superoxide produced by mitochondria under high glucose conditions in human mesangial cells is shown in Figure 4.

Confocal microscopic imaging demonstrated markedly reduced mitochondrial fluorescence intensity of MitoSOX red when human mesangial cells were cultured in $25 \mathrm{mM}$ glucose and treated with MnTBAP compared to $25 \mathrm{mM}$ without MnTBAP and in control cells cultured in $5 \mathrm{mM}$ glucose (Figure 4(a)). A quantitative analysis of the mean intensity indicated a significant decrease in the fluorescence of MitoSOX red at $25 \mathrm{mM}$ glucose and MnTBAP treatment compared to $25 \mathrm{mM}$ glucose without MnTBAP treatment $(P<0.05)$ (Figure 4(b)).

\section{Discussion}

Each human cell contains several hundreds to more than a thousand mitochondria. The copy number of mtDNA varies in different cell types, and when physiological or environmental conditions are changed, mtDNA copy number can be modulated [17]. Results from this in vitro study showed that the copy number of mtDNA is increased in human mesangial following $24 \mathrm{~h}$ incubation in high glucose, and this increase may be due to oxidative stress induced by high glucose. In support of this suggestion, we observed that inclusion of MnSOD mimetic (MnTBAP) during high glucose incubation prevented the increase in mtDNA copy number.

High glucose-induced mitochondrial ROS production has been previously reported in human renal mesangial cells [9-11, 22]. In this study, the accumulation of ROS in human mesangial cells cultured under high glucose conditions was confirmed by increased intensity of DCF-sensitive fluorescence in the cells. Furthermore, the production of mitochondrial ROS by high glucose was confirmed by an increase in fluorescence intensity of the specific mitochondrial MitoSOX red probe, which was inhibited by the addition of MnTBAP during high glucose incubation.

These observations consolidate the results, in which high glucose increases intracellular ROS in human mesangial cells, and support the hypothesis that increased mtDNA copy number of human mesangial cells is caused by oxidative stress resulting from high glucose.

Overproduction of ROS by the mitochondrial respiratory chain may damage mtDNA that is more susceptible to oxidative stress than nuclear DNA $[14,15]$. As a result, the mitochondrial function is compromised, and consequently, ROS production is further increased causing more oxidative damage to mitochondria and mtDNA $[15,16]$.

It has been shown that mtDNA harboring deleterious mutations are preferentially clonally amplified as a compensatory response to energy deficiency by making more mitochondria and mtDNA [25]. Lee et al. [26] reported an 

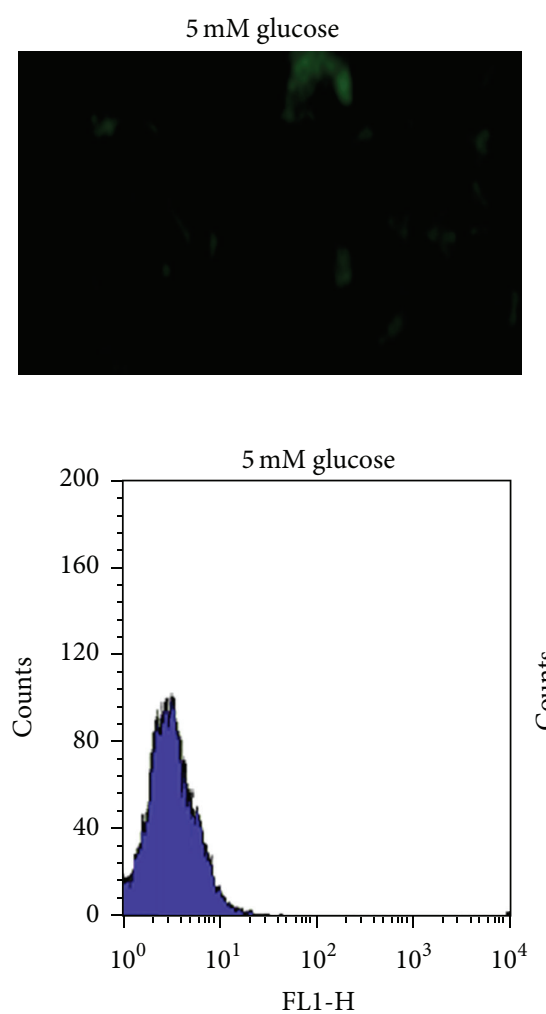

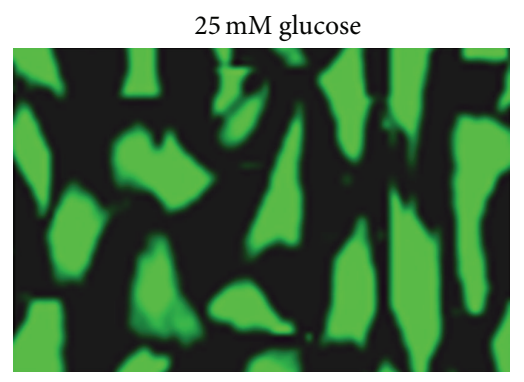

(a)

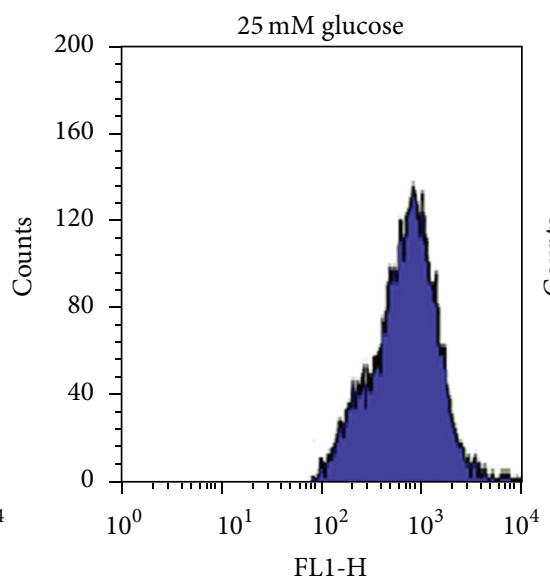

(b)
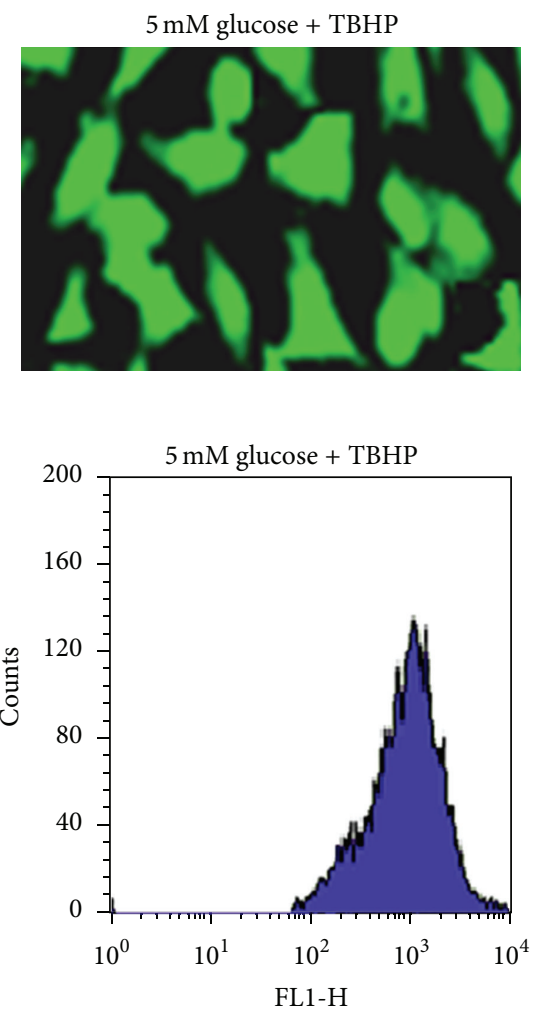

Figure 2: High glucose-induced ROS generation. Synchronized quiescent mesangial cells grown on glass coverslips were incubated for $24 \mathrm{~h}$ with $5 \mathrm{mM}$ glucose or $25 \mathrm{mM}$ and loaded with carboxy- $\mathrm{H}_{2}$-DCFDA $(25 \mu \mathrm{M}, 30 \mathrm{~min})$. Positive control cells were incubated with $5 \mathrm{mM}$ glucose, and treated with TBHP $(100 \mu \mathrm{M}, 1 \mathrm{~h})$, washed and loaded with carboxy- $\mathrm{H}_{2}$-DCFDA $(25 \mu \mathrm{M}, 30 \mathrm{~min})$. Intracellular ROS was detected by confocal microscopy and flow cytometry. (a) Representative confocal images of ROS generation in human mesangial cells. The fluorescent intensity of DCF corresponds to the extent of ROS accumulation. (b) Representative histograms of flow cytometry demonstrating the fluorescent intensity of DCF in human mesangial cells $(n=3)$.

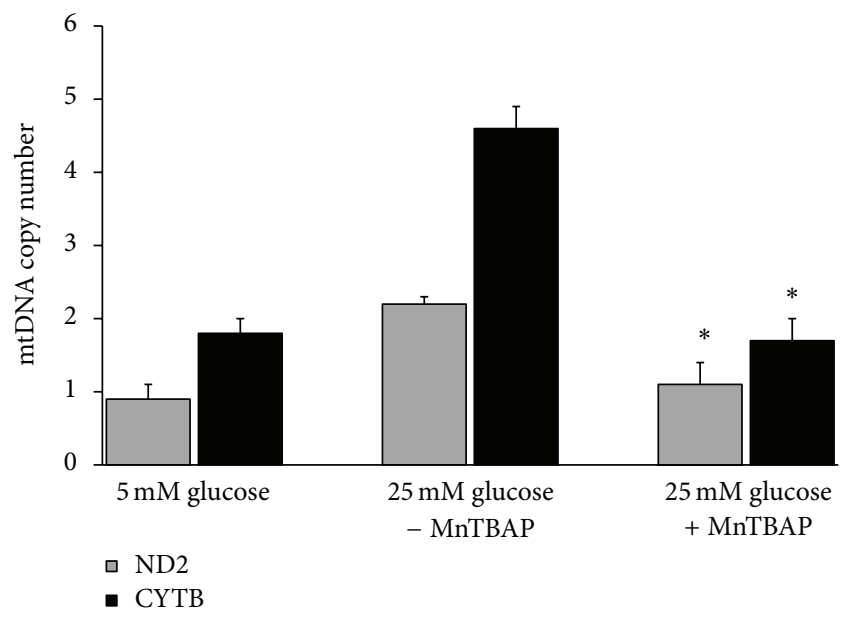

Figure 3: Effect of MnTBAP on high glucose-induced mtDNA copy number. Synchronized quiescent mesangial cells were incubated with $25 \mathrm{mM}$ glucose in the presence or absence of MnTBAP $(200 \mu \mathrm{M})$ or $5 \mathrm{mM}$ glucose for $24 \mathrm{~h}$. The copy numbers of ND2 and CYTB per B2M were determined by real-time PCR. Values represent mean \pm SD of three independent experiments. ${ }^{*} P<0.05$ compared to $25 \mathrm{mM}$ glucose without MnTBAP. increase in mtDNA content following treatment of human lung fibroblasts with $\mathrm{H}_{2} \mathrm{O}_{2}$, which is consistent with the proliferation of mitochondria. An increase in the mitochondrial mass was also observed in skin fibroblasts of myoclonic epilepsy patients compared with those of normal skin fibroblasts [27]. The increase in mitochondrial mass and mtDNA content may be an early molecular event of human cells in response to endogenous or exogenous oxidative stress [26].

The observation in this study that mtDNA copy number is increased in human mesangial cells by high glucose-induced oxidative stress may partially substantiate the evidence of increased mtDNA copy number reported in the blood of diabetic nephropathy patients [5]. Hyperglycemia-induced overproduction of mitochondrial ROS is considered as the central molecular mechanism that activates various biochemical pathways postulated to be implicated in the development of vascular complications in diabetes that include diabetic nephropathy, and increased oxidative stress is believed to be an important contributor [7-9].

It has been shown that hyperglycemia leads to an early inactivation of MnSOD, which in turn increases mitochondrial oxidant production and precedes kidney dysfunction 

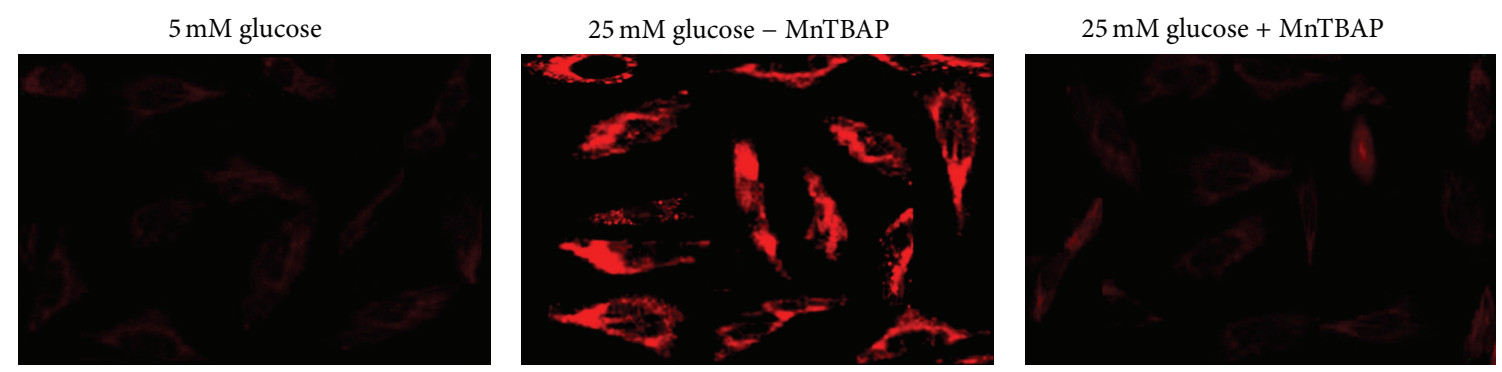

(a)

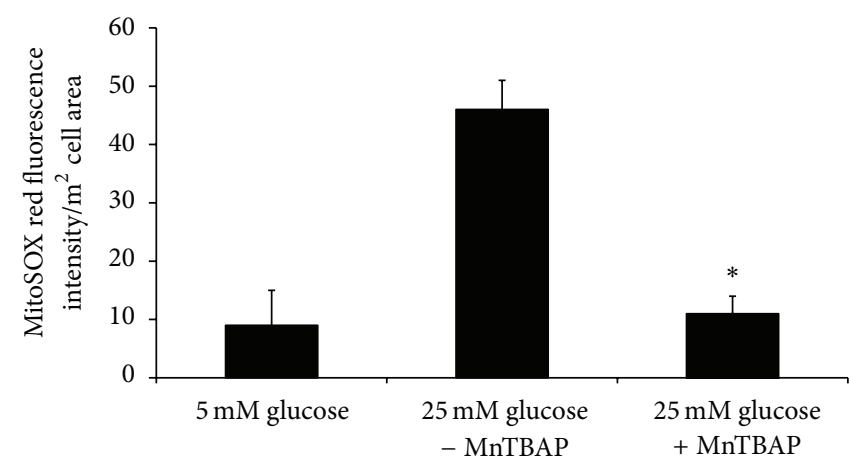

(b)

Figure 4: Inhibition of mitochondrial superoxide by MnTBAP in human mesangial cells. Synchronized quiescent mesangial cells grown on glass coverslips were incubated for $24 \mathrm{~h}$ with $25 \mathrm{mM}$ glucose with and without MnTBAP $(200 \mu \mathrm{M})$ or 5 mM glucose, loaded with MitoSOX $(5 \mu \mathrm{M}, 20 \mathrm{~min})$, and examined by confocal microscopy. (a) Representative confocal images of human mesangial cells showing decrease in mitochondrial MitoSOX fluorescence following incubation of the cells with $25 \mathrm{mM}$ glucose and MnTBAP. (b) Quantitative analysis of the MitoSOX fluorescence intensity per square millimeter cell area in human mesangial cells. Values represent mean \pm SD of three independent experiments. ${ }^{*} \mathrm{P}<0.05$ compared to $25 \mathrm{mM}$ glucose without MnTBAP.

in rat model of diabetic nephropathy [28]. Furthermore, normalizing the levels of mitochondrial ROS with MnSOD prevents the activation of hyperglycemic vascular damaging pathways in diabetes [8], and overexpression of MnSOD suppresses high glucose-induced collagen accumulation in cultured mesangial cells [29].

Hyperglycemia is reported to induce mitochondrial dysfunction, mtDNA oxidative damage, and apoptosis in experimental and animal models of diabetic retinopathy [24, 30, 31]. In animal models of diabetic complications, Kakimoto et al. [32] showed a major role of oxidatively damaged mtDNA in the pathogenesis of diabetic nephropathy.

Increased numbers of mtDNA copies in human mesangial cells by high glucose observed in this study may be a compensatory response mechanism to mtDNA damage and a decline in the electron transport system caused by oxidative stress. At the same time, superoxide and other ROS would be generated from the increased mitochondria in these cells. Consequently, it can cause more oxidative damage to mtDNA and mitochondria with further production of ROS [14]. The beneficial effect of MnSOD mimetic in preventing high glucose-induced mtDNA copy number in human mesangial cells supports a critical role of MnSOD in protecting mtDNA from oxidative injury in diabetic nephropathy. MnSOD is mainly responsible for metabolism of superoxide produced in mitochondria by respiratory chain activity during aerobic metabolism of glucose and other substrates. It is the primary antioxidant enzyme that protects cells from oxidative stress by catalyzing dismutation of superoxide to hydrogen peroxide and oxygen in the mitochondria of eukaryotic cells.

One of the limitations in this study is the lack of timecourse experiments examining the alteration in mtDNA copy number in high glucose cultured-human mesangial cells. In addition, translation of the study findings in the human context is difficult, given that the experimental conditions, mainly exposure to glucose as high as $25 \mathrm{mM}$, are unusual finding in patients with diabetes.

In conclusion, this is the first study to show an increase in mtDNA copy number by high glucose in human mesangial cells that might be a biological adaptation in response to oxidative stress. Protection of mtDNA copy from glucoseinduced mitochondrial ROS by MnSOD could have potential in retarding the development of diabetic nephropathy. Further studies are required to investigate the role of mtDNA copy number in the pathogenesis of diabetic nephropathy.

\section{Acknowledgment}

The authors would like to thank the Diagnostic Services and Research Unit at Al-Jawhara Centre for Molecular Medicine, Arabian Gulf University in Bahrain for their technical and financial supports to conduct this work. 


\section{References}

[1] The Diabetes Control and Complications Trial Research Group, "The effect of intensive treatment of diabetes on the development and progression of long-term complications in insulindependent diabetes mellitus," The New England Journal of Medicine, vol. 329, no. 14, pp. 977-986, 1993.

[2] M. W. Steffes, "Glycemic control and the initiation and progression of the complications of diabetes mellitus," Kidney International, Supplement, vol. 51, no. 63, pp. S36-S39, 1997.

[3] J. Wong, S. V. McLennan, L. Molyneaux, D. Min, S. M. Twigg, and D. K. Yue, "Mitochondrial DNA content in peripheral blood monocytes: relationship with age of diabetes onsetand diabetic complications," Diabetologia, vol. 52, no. 9, pp. 1953-1961, 2009.

[4] J. Song, J. Y. Oh, Y.-A. H. Sung, Y. K. Pak, K. S. Park, and H. K. Lee, "Peripheral blood mitochondrial DNA content is related to insulin sensitivity in offspring of type 2 diabetic patients," Diabetes Care, vol. 24, no. 5, pp. 865-869, 2001.

[5] A. N. Malik, R. Shahni, and M. M. Iqbal, "Increased peripheral blood mitochondrial DNA in type 2 diabetic patients with nephropathy," Diabetes Research and Clinical Practice, vol. 86, no. 2, pp. e22-e24, 2009.

[6] L. L. Montier, J. J. Deng, and Y. Bai, "Number matters: control of mammalian mitochondrial DNA copy number," Journal of Genetics and Genomics, vol. 36, no. 3, pp. 125-131, 2009.

[7] M. Brownlee, "Biochemistry and molecular cell biology of diabetic complications," Nature, vol. 414, no. 6865, pp. 813-820, 2001.

[8] T. Nishikawa, D. Edelstein, X. L. Du et al., "Normalizing mitochondrial superoxide production blocks three pathways of hyperglycaemic damage," Nature, vol. 404, no. 6779, pp. 787790, 2000.

[9] H. B. Lee, M.-R. Yu, Y. Yang, Z. Jiang, and H. Ha, "Reactive oxygen species-regulated signaling pathways in diabetic nephropathy," Journal of the American Society of Nephrology, vol. 14, no. 3, pp. S241-S245, 2003.

[10] H. Ha and H. B. Lee, "Reactive oxygen species amplify glucose signalling in renal cells cultured under high glucose and in diabetic kidney," Nephrology, vol. 10, no. 2, pp. S7-S10, 2005.

[11] M. A. Catherwood, L. A. Powell, P. Anderson, D. McMaster, P. C. Sharpe, and E. R. Trimble, "Glucose-induced oxidative stress in mesangial cells," Kidney International, vol. 61, no. 2, pp. 599608, 2002.

[12] H.-Z. Pan, L. Zhang, M.-Y. Guo et al., "The oxidative stress status in diabetes mellitus and diabetic nephropathy," Acta Diabetologica, vol. 47, no. 1, pp. S71-S76, 2010.

[13] Q. Qian Lu, Y. Zhai, Q. Cheng et al., "Akt/FoxO3a/MnSOD pathway is involved in the regulation of oxidative stress in diabetic nephropathy," Experimental Physiology, vol. 98, no. 4, pp. 934-945, 2013.

[14] T. Ide, H. Tsutsui, S. Hayashidani et al., "Mitochondrial DNA damage and dysfunction associated with oxidative stress in failing hearts after myocardial infarction," Circulation Research, vol. 88, no. 5, pp. 529-535, 2001.

[15] J. H. Santos, L. Hunakova, Y. Chen, C. Bortner, and B. Van Houten, "Cell sorting experiments link persistent mitochondrial DNA damage with loss of mitochondrial membrane potential and apoptotic cell death," Journal of Biological Chemistry, vol. 278, no. 3, pp. 1728-1734, 2003.

[16] V. A. Bohr, "Repair of oxidative DNA damage in nuclear and mitochondrial DNA, and some changes with aging in mammalian cells," Free Radical Biology and Medicine, vol. 32, no. 9, pp. 804-812, 2002.

[17] H.-C. Lee and Y.-H. Wei, "Mitochondrial biogenesis and mitochondrial DNA maintenance of mammalian cells under oxidative stress," International Journal of Biochemistry and Cell Biology, vol. 37, no. 4, pp. 822-834, 2005.

[18] A. Barrientos, J. Casademont, F. Cardellach et al., "Qualitative and quantitative changes in skeletal muscle mtDNA and expression of mitochondrial-encoded genes in the human aging process," Biochemical and Molecular Medicine, vol. 62, no. 2, pp. 165-171, 1997.

[19] A. Barrientos, J. Casademont, F. Cardellach, X. Estivill, A. Urbano-Marquez, and V. Nunes, "Reduced steady-state levels of mitochondrial RNA and increased mitochondrial DNA amount in human brain with aging," Molecular Brain Research, vol. 52, no. 2, pp. 284-289, 1997.

[20] Y.-C. Wang, W.-C. Lee, S.-C. Liao et al., "Mitochondrial DNA copy number correlates with oxidative stress and predicts mortality in nondiabetic hemodialysis patients," Journal of Nephrology, vol. 24, no. 3, pp. 351-358, 2011.

[21] C.-S. Liu, C.-S. Tsai, C.-L. Kuo et al., "Oxidative stress-related alteration of the copy number of mitochondrial DNA in human leukocytes," Free Radical Research, vol. 37, no. 12, pp. 1307-1317, 2003.

[22] G. Al-Kafaji and A. N. Malik, "Hyperglycemia induces elevated expression of thyroid hormone binding protein in vivo in kidney and heart and in vitro in mesangial cells," Biochemical and Biophysical Research Communications, vol. 391, no. 4, pp. 1585-1591, 2010.

[23] A. N. Malik and G. Al-Kafaji, "Glucose regulation of $\beta$ defensin-1 mRNA in human renal cells," Biochemical and Biophysical Research Communications, vol. 353, no. 2, pp. 318323, 2007.

[24] R. A. Kowluru and S. N. Abbas, "Diabetes-induced mitochondrial dysfunction in the retina," Investigative Ophthalmology and Visual Science, vol. 44, no. 12, pp. 5327-5334, 2003.

[25] D. C. Wallace, "A mitochondrial paradigm of metabolic and degenerative diseases, aging, and cancer: a dawn for evolutionary medicine," Annual Review of Genetics, vol. 39, pp. 359-407, 2005.

[26] H.-C. Lee, P.-H. Yin, C.-Y. Lu, C.-W. Chi, and Y.-H. Wei, "Increase of mitochondria and mitochondrial DNA in response to oxidative stress in human cells," Biochemical Journal, vol. 348, no. 2, pp. 425-432, 2000.

[27] C.-F. Lee, Y.-C. Chen, C.-Y. Liu, and Y.-H. Wei, "Involvement of protein kinase $\mathrm{C}$ delta in the alteration of mitochondrial mass in human cells under oxidative stress," Free Radical Biology and Medicine, vol. 40, no. 12, pp. 2136-2146, 2006.

[28] S. Munusamy, R. W. Brock, H. Saba, and L. A. MacMillan-Crow, "Role of manganese superoxide dismutase inactivation in the early stages of diabetic nephropathy," The FASEB Journal, vol. 20, supplement, article A1139, 2006.

[29] P. A. Craven, S. L. Phillips, M. F. Melhem, J. Liachenko, and F. R. DeRubertis, "Overexpression of manganese superoxide dismutase suppresses increases in collagen accumulation induced by culture of mesangial cells in high-media glucose," Metabolism, vol. 50, no. 9, pp. 1043-1048, 2001.

[30] L. Xie, X. Zhu, Y. Hu et al., "Mitochondrial DNA oxidative damage triggering mitochondrial dysfunction and apoptosis in high glucose-induced HRECs," Investigative Ophthalmology and Visual Science, vol. 49, no. 9, pp. 4203-4209, 2008. 
[31] S. A. Madsen-Bouterse, Q. Zhong, G. Mohammad, Y.-S. Ho, and R. A. Kowluru, "Oxidative damage of mitochondrial DNA in diabetes and its protection by manganese superoxide dismutase," Free Radical Research, vol. 44, no. 3, pp. 313-321, 2010.

[32] M. Kakimoto, T. Inoguchi, T. Sonta et al., "Accumulation of 8hydroxy-2'-deoxyguanosine and mitochondrial DNA deletion in kidney of diabetic rats," Diabetes, vol. 51, no. 5, pp. 1588-1595, 2002. 

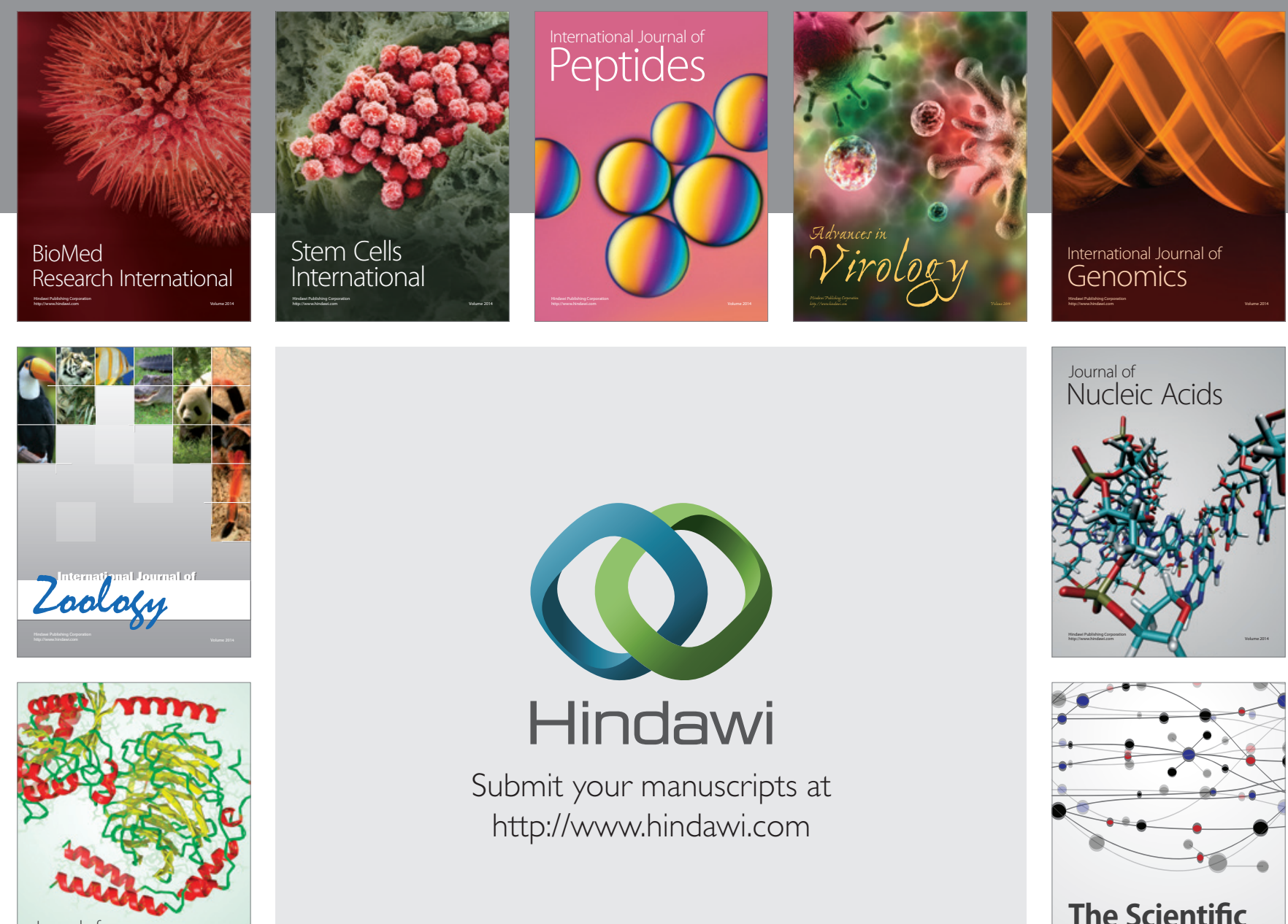

Submit your manuscripts at

http://www.hindawi.com

Journal of
Signal Transduction
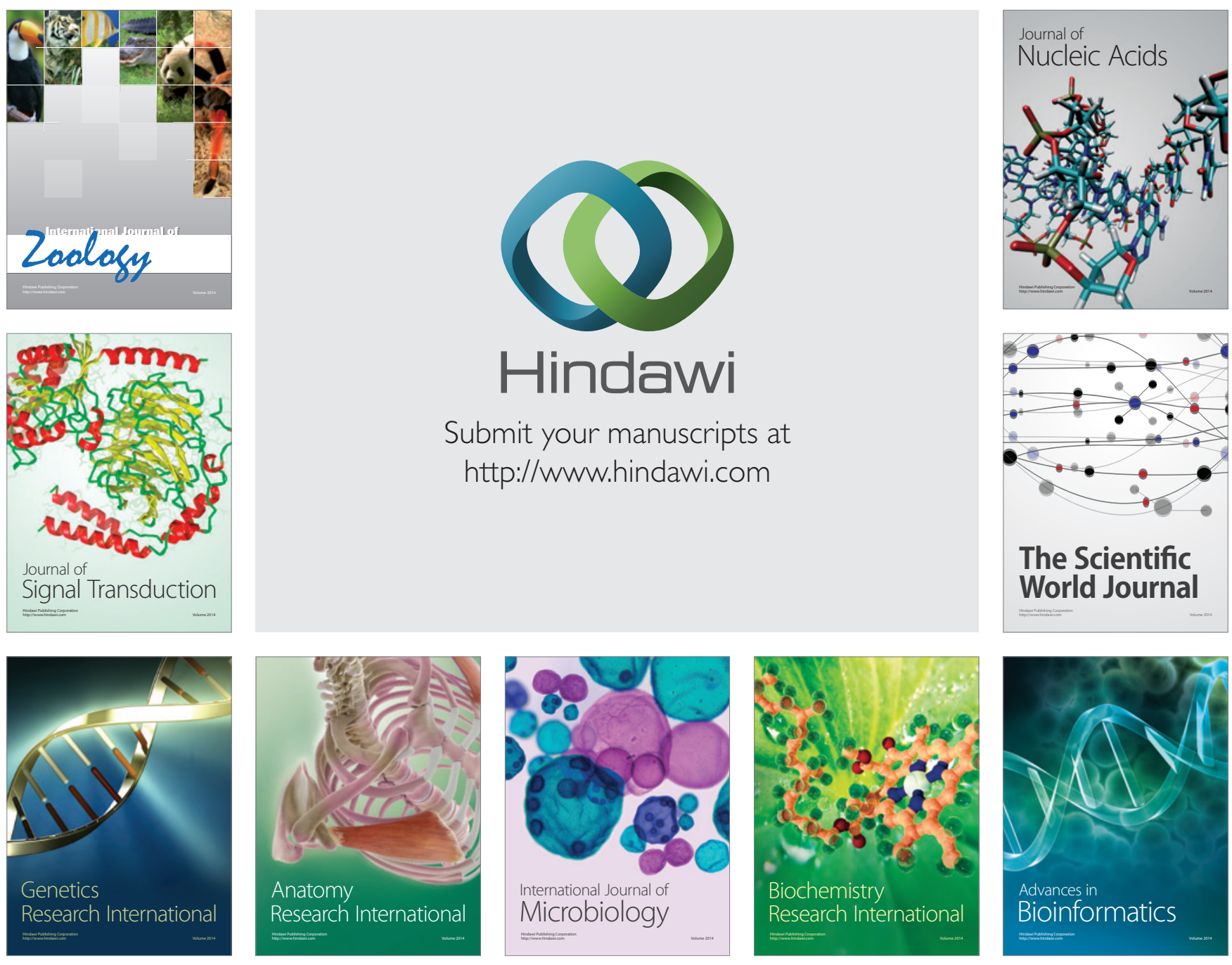

The Scientific World Journal
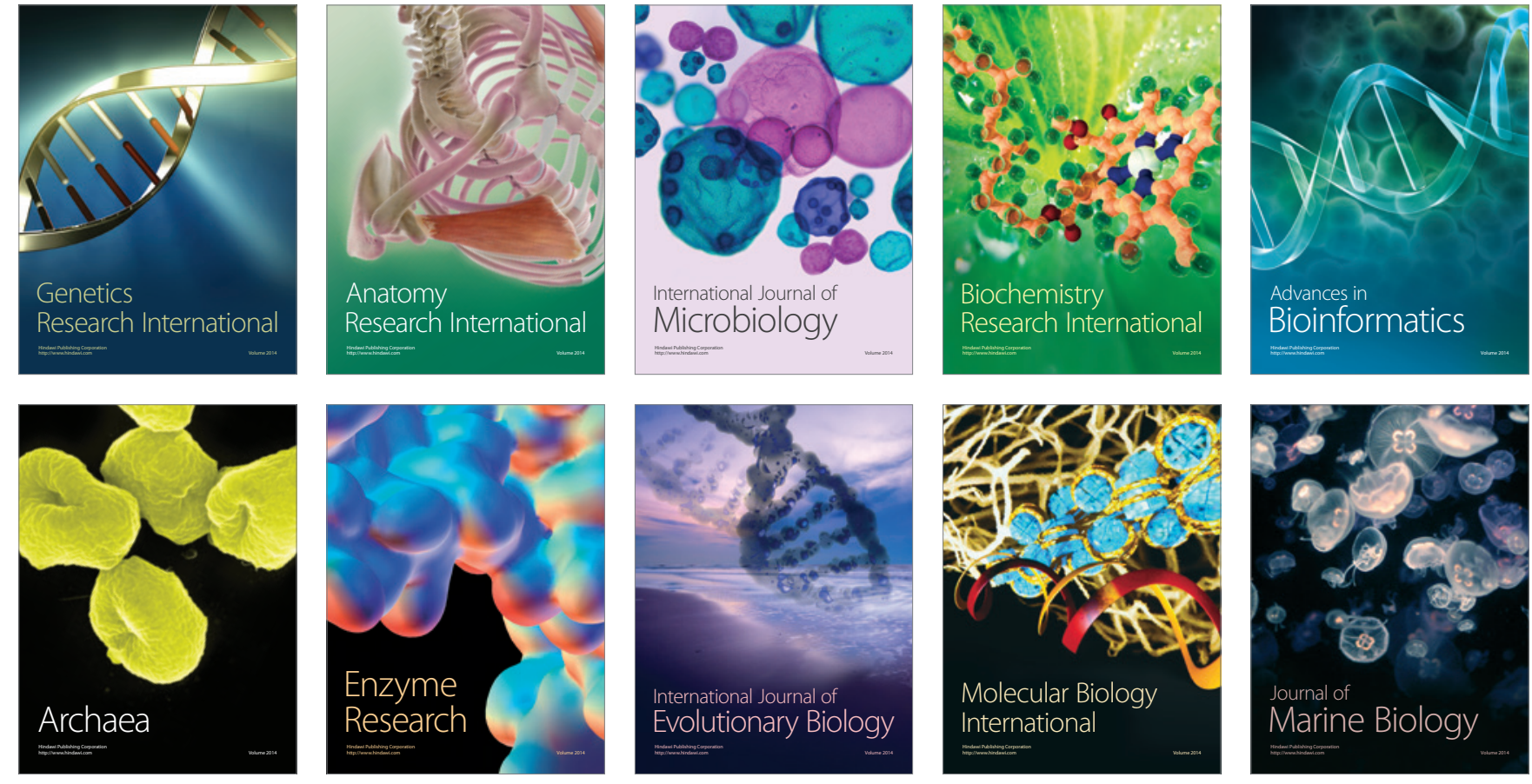